\title{
Uma estranha instituição: novas vozes e os caminhos da crítica literária contemporânea
}

\author{
Ariadne Catarine dos Santos (USP)* \\ https://orcid.org/0000-0001-7398-8636 \\ Claudiana Gois dos Santos (USP)** \\ https://orcid.org/0000-0002-3312-7118
}

\section{Resumo:}

Neste artigo, dividido em três partes, pretendemos especular sobre os conflitos entre as noções de gêneros textuais/ literários e gêneros sexuais a partir do texto A lei do gênero (DERRIDA, 2019) e das políticas do corpo pensadas por alguns segmentos da crítica literária. Para tanto, traçamos um paralelo entre o "falatório" de Stela do Patrocínio, transcrito no Reino dos Bichos e dos Animais é o meu nome (2001), e os escritos de Tatiana Nascimento, em 07 notas sobre o apocalipse ou poemas para o fim do mundo (2019a) e Cuírlombismo literário (2019b). Tais textos nos servem como meios reflexivos para debatermos o lugar dessa Estranha Instituição chamada Literatura (DERRIDA, 2014), espaço que não é apenas de libertação, mas também de reprodução de estereótipos, como demonstram os estudos realizados pela pesquisadora Regina Dalcastagnè $(2012,2018)$ sobre a crítica brasileira contemporânea e a produção literária. Ressaltamos, portanto, em consonância com As ferramentas do senhor nunca derrubarão a casa-grande (LORDE, 2019) e em diálogo com bell hooks (2019), a necessidade de pensar novos modos para o discurso da crítica literária que atuem a partir da compreensão de elementos como raça, classe e gênero.

Palavras-Chave: Crítica Literária, Desconstrução, Poesia, Gênero

\section{Abstract:}

\section{A strange institution: new voices and new ways to contemporary literary criticism}

In this three-part article, we intend to speculate about the conflicts between the notions of textual/ literary genres and gender - using the text Law of Genre (DERRIDA, 2019) as a starting point- and the policies of the body

* Mestra em Letras pelo no Programa: Letras (Estudos Comparados de Literaturas de Língua) Portuguesa), FFLCH- USP. E-mail: ariadne.catarine@gmail.com

** Doutoranda em Letras pelo Programa: Letras (Estudos Comparados de Literaturas de Língua) Portuguesa), FFLCH- USP. E-mail: claudiana_gois@usp.br 
thought by some segments of the literary critic. To do so, we draw a parallel between Stela do Patrocínio's "babble", transcribed in Reino dos Animais $e$ dos Bichos é o meu nome (2001), and two of Tatiana Nascimento's writings: 07 notas sobre o apocalipse ou poemas para o fim do mundo (2019a) and Cuírlombismo Literário (2019b). The aforementioned texts serve as reflective means for us to discuss the place of that Strange Institution called Literature (DERRIDA, 2014), a space which is not only about liberation, but also about the reproduction of stereotypes, as shown by studies carried out by researcher Regina Dalcastagnè $(2012,2018)$ on contemporary Brazilian criticism and literary production. We put emphasize, therefore, in line with The Master's Tools Will Never Dismantle the Master's House (LORDE, 2019) and in dialogue with bell hooks (2019), on the need to think of new modes for the literary criticism discourse which would act from an understanding of elements such as race, class and gender.

Keywords: Literary criticism; Deconstruction; Poetry; Genre/ gender.

Quando eu tô com vontade de falar

Tenho muito assunto muito falatório

Não encontro ninguém pra quem eu possa conversar

Quando não tenho uma voz mais

Não tenho um falatório

Uma voz mais

Vocês me aparecem

E querem conversar conversar conversar

PATROCÍNIO (2001, p. 139)

y esse seu "amor pela Palavra", pela sacralidade da escritura, na real é só um caso histórico de má tradução - que conveniente pra vc, né, chamar deus de "ele"

NASCIMENTO (2019a p.09-10)

\section{Parte I}

Com a realização de um mapeamento sobre a produção da crítica literária acadêmica ${ }^{1}$,

1 Esse mapeamento buscou quantificar e analisar quais são os autores e as obras mais citadas, assim como quantificou quais são as correntes críticas mais presentes, nos artigos publicados nos periódicos mais bem avaliados no ranking acadêmico brasileiro, nos últimos 15 anos. Além disso, o estudo apontou uma possível relação entre os gêneros dos pesquisadores e as escolhas realizadas (DALCASTAGNÈ, 2018). nos "dez periódicos com certa tradição e bem classificados" (DALCASTAGNÈ, 2018, p. 196), segundo os critérios Qualis da Coordenação de Aperfeiçoamento de Pessoal de Nível Superior (CAPES), na área de estudos literários, no período de 2003 a 2015, a pesquisadora Regina Dalcastagnè passou a considerar, pela chave bourdiana, a literatura como um espaço estruturado que segue algumas regras determinadas por agentes específicos, os quais atuam sobre um suporte institucional que é ao mesmo tempo editorial, acadêmico, pedagógico, etc. (DALCASTAGNÈ, 2018). Vista por essa perspectiva, a literatura escapa do lugar sacralizado em que parte da crítica tradicional há muito tenta mantê-la: ela nem se torna por si só um tipo de discurso a que todos têm acesso, nem se torna um discurso que todos produzem. Segundo essa mirada, a literatura atuaria dentro de um campo de forças, sendo determinada por jogos, estratégias e regras bastante específicas.

Para manter o funcionamento desse campo, diversos agentes, entre eles a crítica literária acadêmica, realizam um papel de manutenção e preservação das normas, 
legitimando as obras e autores, os corpos e corpus que podem construir conhecimento e circular em determinados espaços. Como explicita Regina Dalcastagnè (2018, p. 196), o "peso da crítica universitária é visível na definição e redefinição do cânone passado, mas é ainda mais crucial no que diz respeito à produção literária contemporânea".

Essa afirmação leva em conta os dados a partir dos quais a pesquisadora mostra que, apesar de a quantidade de produção acadêmica escrita por mulheres em periódicos ter aumentado nos últimos anos, o mesmo avanço não se mostra na escolha de corpus de textos literários de autoria feminina, nem mesmo na citação de teoria escrita por mulheres (DALCASTAGNÈ, 2018, p. 200), o que marca o espaço da escolha do corpus e das referências bibliográficas como majoritariamente masculino. Tal fato evidencia a "sub -representação feminina" nos trabalhos acadêmicos, sendo que essa sub-representação não apenas é perpassada por questões de gênero, mas também por questões de classe e raça, como se pode observar na seguinte comparação entre a escolha de textos literários de autoria feminina para análise: "o volume de trabalhos sobre Lispector é significativamente maior, 47 no total, enquanto Jesus tem 9 e Evaristo tem apenas $7^{2 \prime \prime}$ (DALCASTAGNÈ, 2018, p. 204).

Além da escolha dos corpos/corpus que circulam no campo literário ser majoritariamente masculina e branca, explicita-se também a predileção por alguns gêneros textuais ${ }^{3}$, como o romance, "considerado o

2 A pesquisadora se refere aos textos de Carolina Maria de Jesus e de Conceição Evaristo, escritoras negras, cuja recepção da crítica devido às questões por vezes de classe, por vezes de raça, podem ter impactado a recepção da crítica em comparação aos textos de Clarice Lispector (DALCASTAGNÈ, 2018, p. 204).

3 Conforme abordado na dissertação "A Bruta Flor do Querer: Amor, performance e heteronormati- gênero literário por excelência, quase que exigindo dos autores/as sua adesão para que possam ser, efetivamente, chamados de escritores/as" (DALCASTAGNÈ, 2018, p. 202). Assim, observa-se também que pesquisadores homens estudam mais a própria crítica literária, o romance e a poesia (esses dois últimos considerados contemporaneamente como grandes gêneros); enquanto "[a]s mulheres trabalham mais com o conto do que os homens e também são as mais propícias a analisar a literatura infanto-juvenil" (DALCASTAGNE, 2018, p. 206-207). Ou seja, o universo masculino parece se dedicar mais aos gêneros da Literatura (com L maiúsculo) - romance e poesia, a própria crítica -, escolhendo como corpus produções de outros homens, normalmente brancos, assim como referenciais teóricos masculinos, igualmente brancos.

Tais considerações expostas por Dalcastagnè (2018) nos movem a realizar especulações sobre o campo literário e o seu funcionamento. Afinal, notamos que a literatura enquanto campo também se estrutura a partir de uma institucionalidade, isto é, assenta-se em modos de atuação entre seus agentes e pelo estabelecimento de pactos para que o sistema funcione e determinados jogos continuem a ser jogados, tendo como base as regras previstas. Todavia, ao mesmo tempo em que esse campo se mantém coeso pelos pactos que o estruturam, ele também se torna um "espaço de disputa" interna e externa, mostrando "a tensão resultante do embate entre os que não estão dispostos

vidade na representação das personagens lésbicas", as leis impostas sobre os limites de cada gênero literário tendem a ser colocadas de maneira mais rigorosa pela crítica quando ela analisa a escrita realizada por mulheres; ao mesmo tempo, tal exigência muitas vezes contribuiu para que, de modo deliberado, as autoras promovessem as contaminações entre gêneros (SANTOS, 2018, p. 38). 
a ficar em seu 'devido lugar' e aqueles que querem manter seu espaço descontaminado" (DALCASTAGNÈ, 2012, p.14). Diante dessa tensão e dos dilemas que essa disputa evidencia, a crítica literária acaba muitas vezes tendo que avaliar dois caminhos que podem ser seguidos:

desconsiderar o julgamento de valor estético sobre a obra e analisá-la a partir de sua especificidade, sem hierarquizá-la dentro de códigos ou convenções dominantes, ou, ao contrário, usar as convenções estéticas mais arraigadas no campo literário para referendar essa obra dissonante, mostrando que ela poderia, sim, fazer parte do conjunto de produções culturais e artísticas consagradas na sociedade, desde que olhada sem preconceito. (DALCASTAGNÈ, 2012, p. 15).

A opção pelo segundo caminho - usando as convenções estéticas tradicionais para validação da literariedade e do valor literário de uma obra - parece ser, em um primeiro momento, o modo mais "seguro" e "reivindicativo", já que se usa do mesmo jogo discursivo e das mesmas técnicas para validar aquilo que parte da crítica pretende excluir. Contudo, como aponta Dalcastagnè (2012), essa escolha não permite "dar o passo seguinte": a indagação sobre a "pretensa universalidade" dos métodos, das definições estéticas, das retomadas históricas que colocam em xeque não só as noções de literatura, como balançam as estruturas que amparam o que se considera como "fazer pesquisa" em Ciências Humanas ${ }^{4}$, a partir de um viés metafísico do questionamento: "O que é?" / "Qual o sentido?".

Especular sobre as bases das definições estéticas, da herança sobre os gêneros (literários/sexuais) dos pactos estabelecidos,

4 Estamos aqui em diálogo com a abordagem de Jacques Derrida a respeito da discussão sobre a linguagem das ciências humanas em A Escritura, o signo e o jogo (DERRIDA, 1971, p. 238) de base metafísica, que determina corpos e corpus e modos de circulação, está no intuito deste artigo, que se configura então como uma entrada no debate acerca dos conflitos entre noções de gêneros textuais/gênero sexualidade, assim como na discussão sobre as políticas do corpo, trabalhadas por alguns segmentos da crítica literária contemporânea, principalmente a crítica feminista interseccional e negra, em diálogo com os aspectos do viés desconstrucionista do discurso derridiano, para refletir sobre a institucionalidade do literário.

$\mathrm{Na}$ emblemática entrevista concedida por Jacques Derrida em 1989, traduzida ao português como Essa Estranha Instituição Chamada Literatura ${ }^{5}$ (2014), Derrida faz provocações quanto às noções de fronteiras entre as áreas das Ciências Humanas, especialmente entre a filosofia e a crítica/teoria literária. Ou, como ele mesmo afirma, há de sua parte uma tentativa de "escapar" dos "próprios estereótipos", não renunciando nem a uma, nem a outra área, como se elas pudessem acontecer e se sustentar separadamente (DERRIDA, 2014, p. 45).

Afinal, como definimos as especificidades de cada discurso e consolidamos qual

5 Jacques Derrida foi entrevistado por Derek Attridge, cujas perguntas foram proferidas em inglês e respondidas por Derrida em francês. As respostas foram traduzidas do francês ao inglês para publicação na coletânea de textos derridianos Acts of Literature. A tradução ao português, realizada por Marileide D. Esqueda, a partir do cotejo da versão em inglês, com revisão de Evandro Nascimento, que considerou também as respostas originais em francês, alinham-se, conforme nota do revisor, à categoria derridiana de inspiração babélica. A menção a esses fatos de tradução que ocorreram de forma parecida com diversos outros textos de Derrida (como A lei do gênero [2019]) nos colocou em face da escolha de com qual das versões dos textos trabalhar. Decidimos, finalmente, pelas versões ao português, com base no desejo da ampliação do diálogo a respeito desses textos em nossa língua. 
tem um caráter mais ficcional e qual tem um caráter de verdade? Para o teórico franco -magrebino, essas fronteiras são estranhamente construídas e apontam aspectos éticos e políticos que entram em tensão, pois se referem às perspectivas sobre as categorias do que pode ser o humano, do que pode ser a língua, do que pode ser a literatura, do que pode ser a racionalidade (SANTOS, 2019). Logo, na entrevista citada, a noção de literatura é colocada como uma invenção recente, criada no contexto europeu, moderno e liberal, que dá espaço "ao escritor para dizer tudo o que queira ou tudo o que possa" (DERRIDA, 2014, p. 52).

No ocidente, atuando enquanto uma instituição, o que se considera literatura transforma-se na lei de dizer tudo-tudo dizer, com o risco de que se afirme: tudo já está sendo dito; logo, as bordas da sua própria institucionalidade estão sendo extrapoladas, de modo que uma noção de literatura se liga imediatamente ao "advento de uma ideia moderna de democracia" (DERRIDA, 2014, p. 51). Sendo que a estranheza dessa instituição fictícia, proclamadora de uma democracia por vir, está em seu próprio jogo: um espaço libertário, de proteção "de toda censura, seja religiosa ou política" (DERRIDA, 2014, p. 54); mas que, ao mesmo tempo, de modo ambíguo, o seu "poder revolucionário pode tornar-se muito conservador" (DERRIDA, 2014, p. 23), reproduzindo estereótipos, obrigando o outro a dizer o que deseja e até mesmo reivindicando uma defesa diante de atos justos e injustos (NATALI, 2006). Tendo em vista o mapeamento inicialmente apontado, especulamos: será que a todos é dado esse espaço de dizer- tudo- tudo-dizer? Como são estipulados os limites da maleabilidade do literário, já que os dados, como os mostrados por Dalcastagnè $(2012,2018)$, apontam limites e exclusões?
Se retomarmos a noção de campo, trazida pela autora a partir de Bourdieu, entenderemos que os textos estão "inscritos numa experiência crítica de literatura" (DERRIDA, 2014, p. 59). Eles são lidos como literatura ou não, são colocados em determinados lugares, já que não há a priori uma essência do literário.

A literariedade não é uma essência natural, uma propriedade intrínseca com o texto, É o correlato de uma relação intencional com o texto, relação esta que integra em si, como um componente ou uma camada intencional, a consciência mais ou menos implícita de regras convencionais ou institucionais - sociais, em todo caso (DERRIDA, 2014, p. 64).

Logo, notamos que há um jogo entre a noção de intencionalidade e de funcionalidade literária. Há textos que são escritos para serem literários e os “'atos' de inscrição e de leitura" os dão credibilidade para assim atuarem; enquanto alguns outros textos apenas funcionam como literários, mesmo não tendo sido construídos intencionalmente para sê-lo. As determinações entre intencionalidade e funcionalidade demonstram aspectos do jogo no campo, pois vemos claramente o papel da institucionalidade crítica que determina muito da institucionalidade literária.

Todavia, não só obras canônicas, como as citadas por Derrida ${ }^{6}$, parecem-nos causar certas provocações ao discurso crítico e retomar questionamentos a respeito de noções que sustentam o campo. Resultado de uma intensa disputa (DALCASTAGNÈ, 2012) pelo campo das narrativas no âmbito

6 Na entrevista Essa Estranha Instituição Chamada Literatura (2014), Derrida aponta Mallarmé, Joyce, Celan, Baitalle, Artaud e Blanchot, escolha totalmente masculina e branca, como autores que colocam em questionamento as noções de literatura. 
social, acadêmico e artístico, a emergência de novos sujeitos, em espaços de criação e de recepção na crítica literária brasileira, tem provocado notáveis desestabilizações no sentido de pensar a pertinência dos instrumentos da crítica tradicional, seja para estabelecer diálogos com novos objetos artísticos, seja para propor diálogos com seus pares no terreno da análise literária.

Sob essa ótica, seguimos a discussão especulando de quais modos as produções como 07 notas sobre o apocalipse ou poemas para o fim do mundo (2019a) e Cuírlombismo literário (2019b), de Tatiana Nascimento, atuam diante desse jogo; e colocamos em questão quais são as provocações que um "falatório" como o de Stela do Patrocínio, transcrito no livro Reino dos bichos e dos animais é o meu nome (2001), podem causar ao discurso da crítica literária contemporânea.

\section{Parte II}

Conforme exposto em A lei do gênero (DERRIDA, 2019), há um jogo semântico intrínseco à palavra gênero e às suas respectivas implicações de leis e normas. Todo corpo (humano/textual) em algum momento, por breve que seja, já foi perpassado pela lei do gênero. É (também) sob as leis do gênero que são erigidos conceitos de valoração, de cânone ou de reconhecimento. Ainda que a lei seja, em português, um substantivo feminino, o poder, instância que decide sobre quem ou como a lei age, permanece nos domínios do masculino (INÁCIO, 2016, p.359). Assim, como nos revelam as pesquisas de Regina Dalcastagnè $(2012,2018)$ apresentadas na primeira parte, parece haver algum tipo de pacto que mantém um sistema de escolha em funcionamento. Conforme os dados comparativos, notamos que esse pacto perpassa questões de gênero, classe e raça, principalmente.
Desse modo, ao observarmos a literatura de autoria feminina, por exemplo, nós vemos de forma dupla - interna e externamente - a marcação do gênero no corpo (textual/ identitário). Observar a existência de uma lei que apela para a origem, para o passado (algo compreendido como natureza); e, ao mesmo tempo, para o que pode ser entendido, ao largo, por cultura (modificações ocorridas ao longo do tempo, em uma determinada sociedade dentro da qual esse objeto "pertence") nos provoca quanto à possibilidade de novas formas de compreender tais produções literárias que ocupam o espaço fronteiriço de pertença e não pertença à lei, ao limite ou à ordenação.

A tentativa de uma outra gramática que dê suporte à leitura crítica de tais obras precisa atentar para as estruturas de pensamento nas quais as ciências humanas têm sido moldadas. Assim, como lemos em $A s$ ferramentas do senhor nunca derrubarão a casa-grande, fala proferida pela escritora e pesquisadora Audre Lorde (2019), em que se afirmam os limites restritos para as mudanças possíveis, quando se usam ferramentas de um patriarcado racista para examinar ações que, por vezes, ao tentar abalar uma estrutura, podem ainda mais reforçá-la.

0 poder imputado à crítica (ou ao mercado leitor) para estabelecer critérios qualitativos; ou ainda, o poder de determinar quais experiências humanas são dignas ou não de estarem inscritas no terreno literário, bem como as decisões sobre formas de representação que respeitem singularidades de grupos tradicionalmente estereotipados, evoca a atenção para "a necessidade que a linguagem carrega em si de sua própria crítica” (DERRIDA, 1971, p. 237), uma vez que o movimento de inserção/aceitação/ aumento dessas presenças na produção/representação/crítica literária, conforme vi- 
mos anteriormente com Regina Dalcastagnè $(2018,2012)$, não necessariamente torna o meio literário um espaço mais justo, diverso, inclusivo, visto que ainda são estreitos os limites para possíveis modificações.

A obra Reino dos bichos e dos animais é o meu nome (2001), que contém a transcrição das falas de Stela do Patrocínio, por exemplo, causa uma série de problematizações quanto ao seu lugar dentro do campo literário, já que esse livro é um objeto mediado por diversas mãos ${ }^{7}$, para além de um projeto intencional de literatura. A saber, Stela do Patrocínio foi uma paciente psiquiátrica que passou 30 anos internada em hospitais psiquiátricos no Rio de Janeiro, enfrentando os ditames de uma clínica psiquiátrica eugenista ${ }^{8}$. Com os movimentos de reforma psiquiátrica a partir do final de 1970 e início da década de 1980, ela também "participou" de outro momento do discurso psiquiátrico e mesmo artístico, pois pôde "participar" da criação do Ateliê de Livre Expressão Artística, no Núcleo Teixeira Brandão onde vivia. Como descrevem as psicólogas e artistas plásticas envolvidas no projeto, Stela não participava ativamente das atividades do Ateliê, mas passava pelo espaço, ia e voltava, falava. E foi o seu "falatório", modo como ela definia as próprias falas,

7 A dissertação $O$ falatório de Stela do Patrocínio e o discurso da crítica literária: variações (SANTOS, 2019), refletindo sobre as provocações que a formulação do livro Reino dos bichos e dos animais é o meu nome (PATROCÍNIO, 2001) causam à crítica literária, debate algumas das questões de herança que sustentam o discurso da crítica literária, pensando nos modos de produção, recepção e mediação dessa obra, assim como especula sobre algumas possíveis leituras para 0 "falatório" que a compõe.

8 Inicialmente, em 1962, Stela foi internada no Centro Psiquiátrico Pedro II, e, posteriormente, em 1966, foi transferida para a Colônia Juliano Moreira. Esse segundo lugar foi caracterizado como a "cidade dos rejeitados", o "depósito dos loucos", destinado aos sujeitos irrecuperáveis. (SANTOS, 2019, p. 29). que chamou a atenção, especialmente da artista plástica Carla Guagliardi e da estagiária em psicologia Mônica Ribeiro, que gravaram as falas com um gravador "comportado" que parecia um "livro de reza", como também definia Stela do Patrocínio ao se referir aos momentos em que ficavam "sentados numa cadeira procurando/mesa/Procurando falatório/Procurando gravar o falatório todo" (PATROCÍNIO, 2001, p. 138).

Após o término das atividades do Ateliê e do falecimento de Stela, esse "falatório" ficou mais uma vez escondido/silenciado e só voltou a ser procurado no final da década de 1990, quando a filósofa e escritora Viviane Mosé, sabendo dessa história, recuperou as fitas com as falas e buscou as transcrições já feitas, transformando-as em livro. Reino dos bichos e dos animais é o meu nome (2001) é então um trabalho mediado por diversas mãos, desde o processo de gravação até a construção do objeto livro, o que coloca em tensão o papel do intelectual como mediador diante de vozes subalternizadas e os limites éticos e estéticos desse processo de mediação.

No livro em questão, a disposição dos textos em formato de poemas em sua maioria, por exemplo, indica escolhas políticas sobre as noções de língua e literatura e dos gêneros que as constituem (SANTOS, 2019, p. 51). Trazemos esse imbricado jogo em questão já que a própria Stela, como está disposto no livro, ao receber o pedido para falar uma poesia, reitera que: "Não/Não tenho mais lembrança de poesia mais/ nenhuma". Confrontando a ideia exposta de que tudo o que ela falava era poesia, ela responde: "É só história que eu tô contando, anedota" (PATROCÍNIO, 2001, p. 153). Quiçá, a classificação das falas em "anedota" pudesse indicar uma outra forma de olhar para o próprio discurso, indicando também 
o que permanece de singular, aquilo que não foi editado, que pode não ter sido moldado pelo processo de mediação, pela passagem do oral para o escrito, pela formulação de um livro (SANTOS, 2019).

Tais movimentos entre o que é definido por um mediador ou uma instância de autoridade e aquilo que diz um sujeito em uma situação subalternizada retoma o questionamento de Gayatri Chakravorty Spivak ${ }^{9}$ (2010): Afinal, pode o subalterno falar? Pelo desdobramento dessa indagação, também podemos questionar: quando o sujeito subalternizado fala, ele é de fato escutado? 0 livro com as transcrições das falas de Stela do Patrocínio mostra que muitas vezes para o sujeito subalternizado ser escutado o seu "falatório" precisa ser categorizado como literatura. Por isso, esse livro em questão atua como um meio reflexivo para repensarmos as práticas críticas que lidam diretamente com essas novas vozes, visto que ações como falar sobre, falar por, decidir a autoria, escolher o formato por aquilo que é mais rentável extrapolam as bordas de espaço literário que se diz democrático (SANTOS, 2019).

Ainda em Reino dos animais e dos bichos é o meu nome (2001) há um determinado trecho transcrito em que as colocações de Stela apontam um seguinte jogo entre o silenciamento e a falação sem fim na busca por algo que o intelectual deseja, ela afirma, por exemplo, que quando tinha vontade de falar, não encontrava ninguém para conversar, mas quando estava sem voz, apareciam querendo "conversar conversar conversar" (PATROCÍNIO, 2001, p. 139).

9 Spivak, leitora e tradutora de Derrida, em sua famosa obra Pode o subalterno falar? (2010) questiona particularmente a situação das mulheres na sociedade colonial indiana e problematiza as matrizes da lógica euro-logocêntrica que sustentam os discursos ocidentais, principalmente as metodologias com as quais se analisa a situação de pessoas em alguma situação de subalternização.
Eu já não tenho mais voz

Porque já falei tudo o que tinha que falar

Falo, falo, falo, falo o tempo todo

E é como se eu não tivesse falado nada [...]

(PATROCÍNIO, 2001, p.142)

As ambiguidades entre o falar e o não querer falar ${ }^{10}$, entre o lugar e não lugar do discurso de pessoas em sofrimento psíquico, por exemplo, são demonstradas também pelas escolhas dos agentes dentro do campo literário; como eles determinam esses discursos. Se o livro foi transcrito majoritariamente no formato de poemas, ao ser avaliado para um possível Prêmio Jabuti ele foi categorizado como pertencente à área de Psicologia e Educação, sendo visto predominantemente por seu teor documental. 0 que nos explicita que, a depender da escolha ética e política dos agentes, tais discursos de sujeitos subalternizados giram em torno da funcionalidade e da intencionalidade literária.

Torna-se importante frisar, em paralelo às classificações de leitura pela funcionalidade ou intencionalidade de textos - como o "falatório" de Stela do Patrocínio -, os modos como outras perspectivas, adentrando questões também pertinentes à crítica, como classe e raça, podem propiciar leituras diversas de uma mesma obra. Em diálogo com a pesquisadora Rosane Borges, no pre-

10 Na História da Sexualidade I: A vontade de saber, de Michel Foucault, a ambiguidade entre falar e não falar é explorada a partir da "codificação clínica do 'fazer falar'”, como um confessionário em busca de uma verdade sobre o sujeito. Observadas as diferenças dos contextos históricos mencionados em Foucault e no presente trabalho, destacamos como certas esferas do poder atuam, sobretudo, como um autorrelato dos corpos femininos e como a frequente associação entre traços atribuídos ao feminino e aos estados de loucura podem, por vezes, demandar determinadas estratégias por parte do sujeito que sofre, como o silêncio e a recusa, não como interdição, mas como proteção (FOUCAULT, 2014, p.73) 
fácio à edição brasileira de Olhares Negros: raça e representação (bell hooks, 2019), vemos que a proeminente disputa por espaços ocupados no imaginário social colocada pelas novas vozes sociais, sejam elas autorais ou da crítica literária, diferenciam-se da crítica tradicional por levar em consideração as reivindicações de grupos historicamente discriminados, tensionando (muitas vezes, sem estabelecimentos de hierarquia) as possibilidades múltiplas de leituras dos textos, como os atribuídos a Stela do Patrocínio, ao observar a força que tais olhares adquirem quando consideradas as imbricações dos marcadores de raça e gênero, por exemplo.

Logo, a tensão instaurada por obras como Reino dos bichos e dos animais é o meu nome (2001) nos leva a questionar os limites do contexto de produção; ou mesmo os limites que a crítica costuma colocar na análise literária como ferramentas de controle, como: biografia da autora, totalidade da obra, contexto histórico, visto que quando observamos obras como a que contém o falatório de Stela do Patrocínio (e mesmo o terreno da autoria não é consensual entre partes da crítica) talvez tenhamos, ainda que parcialmente e parcimoniosamente, "renunciar à episteme como exigência absoluta, que é a exigência absoluta de procurar origem, o centro, o fundamento" (DERRIDA, 1971, p.241) para assim, conseguir ouvir vozes que por muito tempo estiveram fora do campo em que o jogo da literatura é posto.

E, talvez, caiba ressaltar a insuficiência da inclusão dessas vozes em um campo que muitas vezes reproduz exclusões de ordem social, visto que a mera inclusão e a respectiva visibilidade concedida à emergência dessas vozes e de suas obras, na condição de fenômenos isolados e não como uma abertura real do campo a quaisquer sujeitos, pode fortalecer ainda mais a tradição que estrutura o campo da literatura - majoritariamente de classes mais altas, brancas, heterossexuais e masculinas.

Em face disso, a discussão pode ser espraiada, conforme já mencionamos anteriormente, tanto na direção da crítica quanto na direção do sujeito que escreve literatura, como condição de pensar uma escrita tensionada entre os campos do fazer artístico e da responsabilidade ética sobre o discurso publicado, uma vez que "é preciso defender uma ação transformadora capaz de encontrar maneiras de (re)inventar um mundo possível, numa perspectiva estética, ética e política" (BORGES, 2019, p.11).

Seguindo a discussão, obras como 07 notas sobre o apocalipse ou poemas para o fim do mundo (2019a), de Tatiana Nascimento, tensionam tais exigências partindo do descentramento por meio da representação de vozes emergentes e podem nos valer como meio reflexivo para observar movimentos fronteiriços intencionais provocados desde a capa. Tradicionalmente, a capa é um espaço pensado para trazer informações editoriais que delimitam a leitura por meio da inscrição da obra em um determinado gênero literário (romance, poesia, contos). Essa inscrição, que antecede a narrativa, direciona a compreensão do leitor propiciando uma espécie de invólucro, algo muito próximo ao que Derrida nomeia de invaginação ${ }^{11}$, fazendo com

110 conceito de invaginação surge neste ponto como uma espécie de "traço que marca o pertencimento [e] aí se divide, sem falta, a borda do conjunto acaba formando, por invaginação, um compartimento interno maior do que o todo (DERRIDA, 2019 p.255). Ou ainda, a inscrição do índice na capa de um livro de notas ou poemas formaria uma borda na leitura dos textos, causando, junto com os títulos dos poemas inscritos na capa, compartimentos internos em termos de compreensão dos gêneros literários. Tal efeito se daria inicialmente por meio da evocação de títulos que parecem contaminados por outros gêneros (artigos científicos: "cientistas subno- 
que, intencionalmente, pré -concepções sobre a leitura envolvam o conteúdo, sem que necessariamente o conteúdo pertença àquela ideia inicial inscrita ainda na capa.

Em 07 notas sobre o apocalipse ou poemas para o fim do mundo (2019a) pode-se imaginar uma contaminação entre os gêneros textuais, notas e poemas unidos em um título (ou dois), antes da abertura do livro. Assim, desde a capa os rigores de pertencimento às leis do gênero literário são questionados. A própria divisão entre exterior e interior é revista pela espécie de sumário impresso na capa da obra, e mesmo a orelha do livro, espaço comumente utilizado para a apresentação, em vez disso, nos traz uma espécie de guia ou advertência para a leitura:

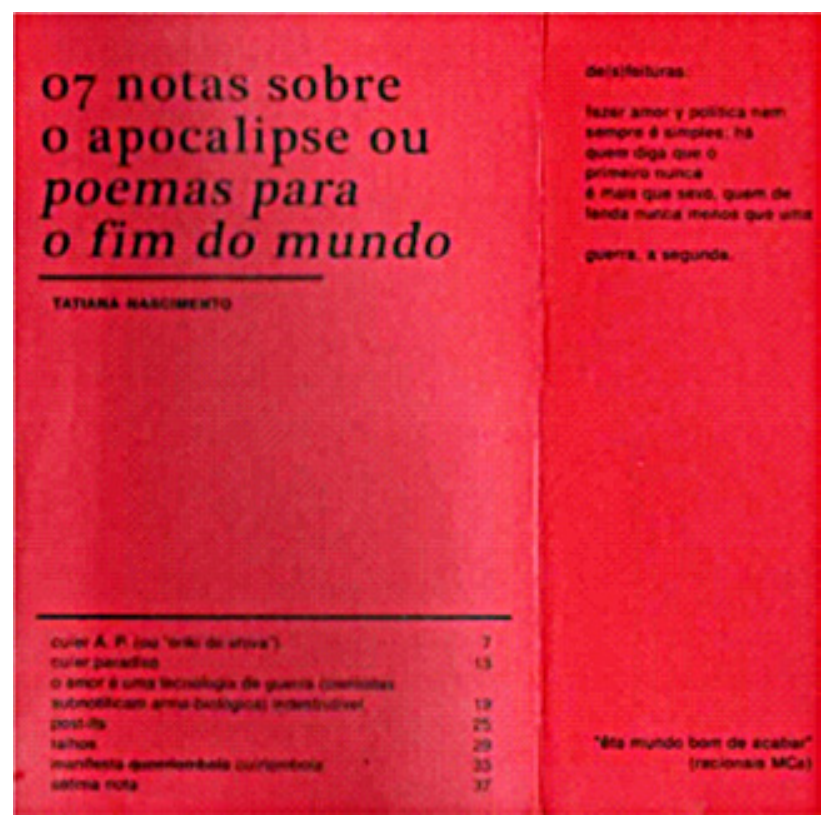

de(s)feituras:

fazer amor y política nem

sempre é simples; há

quem diga que o

primeiro nunca é mais que sexo, quem de fenda nunca menos que uma

tificam arma-biológica"; manifestos: "manifesta queerlombola cuírlombola"; ou mesmo "notas"). Tal evocação cria ao redor dos textos uma possibilidade de contaminação de outros gêneros textuais, dentro do próprio gênero inicial estabelecido como um livro de poemas. guerra, a segunda.

(NASCIMENTO, 2019a)

Considerar a orelha uma portadora de uma advertência sobre os dois eixos temáticos que guiam as notas/poemas - amor e política -, é compreender, no livro em questão, a concepção de Nascimento ${ }^{12}$ em diálogo com o duplo sim derridiano (DERRIDA, 2019, p.251). Em outras palavras, ao intentar a ruptura com conceitos clássicos do gênero e com as leis formais que um texto deve ter para pertencer a determinado gênero (DERRIDA,2019, p.261), Tatiana Nascimento rompe com a lógica do sim ou do não, apontando para possibilidades de atuação em lógicas presentes em outras produções literárias (INÁCIO, 2016, p. 360), que acenam para a possibilidade de serem dois ou mais gêneros ao mesmo tempo, sem que haja necessariamente uma busca pela compreensão total, semântica ou estética do texto literário ao ser poesia e nota e advertência.

As lógicas atuantes em 07 notas para $o$ apocalipse ou poemas para o fim do mundo, desde a capa, estão dispostas em sobrecamadas e simultaneamente evocam possibilidades amplas e diversas de leitura. De acordo com Nascimento, a

[...] literatura é dessas artes com as quais inventamos mundos novos, im ou possíveis, utópicos, diz-tópicos: fundamos lugar no dizer. criamos kuírlombos não só de resistência: mas de sonho, de afeto, semente (NASCIMENTO, 2019b, p.24)

12 Evidencia-se a atuação de Tatiana Nascimento como alguém que, além de criadora, pesquisadora e artista, atua como editora e, portanto, conhece os meandros da produção literária para além do espaço de autoria. Seu projeto Padê Editorial é voltado para a produção autoral LBTQ. Selecionada pelo Fundo Elas de Investimento Social, publicou mais de 60 pessoas LBTs, $80 \%$ delas negras. Disponível em: http://pade.lgbt/ sobre/. Acesso em: 11 set. 2020. 
Em um plano talvez mais verticalizado na semântica do texto, as inesperadas quebras dos versos (fazer amor y política nem/sempre é simples; há/) promovem jogos com as possibilidades de leitura, como entre o primeiro e o segundo verso, nos quais a palavra "nem" pode proporcionar sentidos diferentes quando lida e/ou não lida em cada verso. O mesmo movimento ocorre com a quebra da palavra "de fenda", que pode assumir, na possibilidade de leitura polissêmica, a partir da percepção de que o amor evocado na economia dessa obra trata-se, muitas vezes, do amor entre duas mulheres, um descentramento da ordem heteronormativa geralmente representada na literatura.

Retomando o caso de Stela do Patrocínio, vemos que seu "falatório" é constantemente reivindicado por perspectivas críticas diferentes, não necessariamente excludentes. A sua publicação pode ser vista como uma espécie de ascensão ao campo da literatura, alçando-o para o campo "sublime" do fazer literário; enquanto outros setores da crítica abordam prioritariamente os aspectos da violência, da dor e da reclusão daquele corpo negro, feminino e socialmente "impróprio" para a convivência em liberdade.

Considerando Reino dos bichos e dos animais é o meu nome e 07 notas para o apocalipse ou poemas para o fim do mundo, em um paralelo com as ideias propostas pelo ensaio crítico Cuírlombismo Literário (2019b), também de Tatiana Nascimento, ainda que se pesem aqui, além dos pontos de semelhança entre as obras, também as divergências de contexto histórico e de produção, a intencionalidade dos discursos e o domínio sobre seus meios de publicação, compreendemos que uma proposta de criação e recepção literária demanda posicionamentos éticos, políticos e também estéticos que entendam a desconstrução como uma forma afirmativa de utilização de novas ferramentas analíticas para as artes. Algo que rompa com uma tradição estabelecida nos dois campos, e atue para além da denúncia e da dor,

tanto episteme teórica quanto nutriz de imaginários, ficcional. [...] (ler) poemas e versoschave sob a responsabilidade y o desafio de entender e difundir nossa produção literária da diáspora sexual-dissidente não só como ferramenta de desconstrução/ desmonte dos pilares hiperheterocissexualização e silenciamento, mas como re-fazendo, re-feitura, y além da reação (NASCIMENTO, 2019b p.20)

Desse modo, ao observarmos produções como as de Tatiana Nascimento, é possível pensar na sua intencionalidade de romper com padrões pré-estabelecidos no campo da literatura, provocando tensões a partir da desestruturação. Esse processo pode ser visto desde os níveis mais imediatos da leitura - como o uso dos sinais gráficos de parênteses e colchetes, de modo a evidenciar um pensamento em construção - até os níveis semânticos, com uma proposta que vai além de uma literatura de resistência (cuja importância não é descartada pela autora, ainda que ela pareça ter como horizonte um passo futuro após o resistir ao sofrimento), oferece novos modos de ficcionalizar o mundo.

O aparente objetivo de Nascimento, que emerge à leitura Cuírlombismo Literário (2019b), é, a partir do conhecimento e da disseminação da produção realizada pelo que a autora nomeia de diáspora sexual-dissidente, provocar mais que a desconstrução, instituir um futuro que ainda não foi nomeado, em termos de crítica e de produção ficcional, colocando em permanente tensão os jogos estabelecidos pela instituição literatura. Mais uma vez, reafirmando que não 
basta que um ou outro fenômeno emergente seja incorporado pelo cânone, ou mesmo que se crie um outro cânone, mas que haja outras ferramentas que não as do "senhor" para construir modos outros de críticas literárias, ou ainda, um

outro lugar dos gestos de desobediência, da atitude revolucionária, para laborarmos em prol da emergência de outras ordens de representação que supõe a adoção de outros olhares [...] a ideia de que as experiências de luta das mulheres negras sejam consideradas para além do registro da dor e da falta (BORGES, 2019, p.12, 18).

Assim, tanto na obra com o "falatório" de Patrocínio quanto nas poesias e no ensaio de Nascimento, é possível especular sobre os agenciamentos da lei do gênero sobre os corpos (textuais/identitários) no sentido do estabelecimento de limites que, ao apelarem retrospectiva e prospectivamente, atuam sobre as possibilidades de circulação e valoração do pensamento artístico e crítico das novas vozes que emergem no campo dessa estranha instituição chamada literatura.

\section{Parte III}

Pela breve apresentação e análise das obras, percebemos que algumas das inscrições marcadas (ou não) no corpo do texto, por quem escreve ou edita, podem alterar as formas de recepção do objeto pela crítica e pelos leitores. A depender do gênero literário, do gênero identitário e da incidência das leis do gênero sobre esse corpo/corpus (poesia, ficção, crítica literária, autoria feminina, negra, lésbica, pessoa em situação de sofrimento psiquiátrico), as inscrições artísticas/críticas podem ser modificadas quanto aos modos de circulação, recepção, análise e crítica. $\mathrm{Ou}$, ainda, notamos que as questões relacionadas ao pertencimento criam um movimento, talvez, um jogo contí- nuo de pertencer a todas e a nenhuma dessas inscrições ao mesmo tempo.

Em outras palavras, o fluxo entre as ideias de Derrida (1971, 2014, 2019), Lorde (2019), Dalcastgnè $(2012,2018)$, Borges (2019), hooks (2019), Natali (2006), Nascimento (2019a, 2019b) e Patrocínio (2001) parece seguir na direção de que os movimentos para a construção de uma crítica feminista, interseccional e decolonial precisam, além de disputar o campo literário, atentar para a armadilha de utilizar os velhos parâmetros como base quando se deseja construir olhares outros para os objetos.

É importante evidenciar que não há neutralidade no campo literário, ou nos jogos de tensão entre crítica, autores e leitores. Algumas estruturas como a cultura de discriminação de raça, de classe e de gênero que permeiam a sociedade brasileira também são critérios (mais ou menos indiretos) para a determinação de quem pode acessar os espaços de prestígio da escrita, do reconhecimento da crítica e da comercialização para o grande público. Dificilmente, a arte se moveria sem mudanças nas estruturas sociais; do mesmo modo, as obras ficcionais, vez ou outra, causam determinados abalos que iluminam as frestas possíveis pelas quais emergem agentes "estranhos" à instituição tradicional da literatura.

Por isso, um espaço de múltiplas possibilidades pode, eventualmente, servir à desconstrução (ao repensar elementos internos a uma estrutura hierárquica como são os cânones) e à desestabilização, a partir da fundação de novas perspectivas críticas plurais y interseccionais o suficiente para

nos livrar da mirada htcisnormativizante que a colonialidade impõe às nossas trajetórias/existências/simbologias pré-atlânticas, como tentativa de planificar e rasificar; mais fácil dominar narrativas, sexualidades, prá- 
ticas, existências de sujeitos [...] que escapam ao binarismo homem/mulher católico branco tido como parâmetro de sexualidade. [...] assentar nossa poética em aqueerlom= bamento-acuírlombamento foi outra jornada: entender o remontar-se/recriar-se pelas palavras como um fazer mítico-político, reinvenção [...] a partir de nossas próprias narrativas ancestrais (NASCIMENTO, 2019b p.10).

Torna-se necessário e urgente, portanto, ter em conta as questões coloniais que por muito tempo encarceraram nossa forma de rever as nossas próprias práticas enquanto pessoas que atuam nos jogos da estranha instituição chamada literatura. Os sujeitos emergentes, as novas vozes do campo literário em disputa, exigem para si miradas mais amplas, algo para além

"do estéril jogo de palavras que tão frequentemente e de modo distorcido, os patriarcas brancos chamam de poesia - a fim de disfarçar um desejo desesperado de imaginação sem discernimento" (LORDE, 2019 p. 46).

E, se por muito tempo, em grande parte da crítica literária brasileira predominaram lógicas que, em sua estrutura, traziam ecos do preconceito e da depreciação, aliadas às práticas de extermínio epistemológico dos corpos/corpus a serem dominados, pode ser importante aqui destacar que, apesar de muitos pontos das propostas de pensamento de Tatiana Nascimento dialogarem, de modo próximo, com às proposições derridianas de desconstrução, a evocação de uma ancestralidade (compreendida como pertencimento ao povo negro) a diferencia dessa perspectiva, colocando-a em diálogo mais profundo com as proposições presentes nos textos de Audre Lorde (2019) e bell hooks (2019).

Longe de uma leitura facilmente essencialista que poderia estabelecer tal proximidade pelo recorte de serem três mulheres negras, as proposições estéticas, políticas e éticas dos textos sugerem leituras mais complexas. Se pensarmos, por exemplo, o sentido de urgência apocalíptica do discurso, tendo em vista o gênero apocalíptico como um modo de circunscrever a necessidade de um povo de acreditar na destruição de um sistema de opressões (SOARES, 2008, p.100). Temos, por exemplo, em 07 notas sobre o apocalipse ou poemas para o fim do mundo (2019a) referências à impossibilidade de edificação de novas formas de pensamento sobre o solo devastado das ideias de hierarquia de gêneros, corpos, ideias. Desse modo, o apelo à primeira pessoa do plural, em diversas partes do ensaio Cuírlombismo literário (2019b), nos traz, além das diferenças importantes em comparação com as proposições de Derrida, o senso de compromisso prático e, principalmente, urgente, no sentido epistemológico e crítico, observado ao logo das obras de hooks (2019) e Lorde (2019).

Precisamos considerar como as relações imbricadas pelas leis do gênero que afetam o corpo/escrita de Derrida são, em muitos aspectos e graus, diferentes das injunções que as leis da lei de gênero impõem aos corpos/corpus de Stela do Patrocínio, de Tatiana Nascimento, e também, em seus respectivos contextos temporais e geográficos, de bell hooks e de Audre Lorde. Talvez, seja oriundo das diferentes implicações o senso de urgência e a ancestralidade evocada nos textos de Tatiana Nascimento. A proposição do coletivo, a partir da primeira pessoa do plural, e a construção dissidente, quiçá, seja o passo que a autora encontrou para ir além da reivindicação e chegar no futuro posterior ao apocalipse por ela anunciado. Algo que alcance pontos que não puderam ser vislumbrados pelo espaço corpo/corpus ocupado por Derrida, mas que, de certo 
modo, dialoga com as ferramentas críticas que ele apontava como

o ainda inominável que se anuncia e que só se pode fazê-lo, como é necessário cada vez que se efetua num nascimento, sob a espécie da não-espécie, sob a forma informe, muda, infante e terrificante da monstruosidade (DERRIDA, 1971 p.249)

De certo, tais movimentos críticos não se mostram como empreitadas simples, visto que

"não podemos enunciar nenhuma proposição destruidora que não se tenha já visto obrigada a escorregar para a forma, para a lógica e para as postulações implícitas daquilo mesmo que gostaria de contestar" (DERRIDA, 1971, p.233).

Por isso a importância de se observar atentamente o propósito da crítica e reconhecer os movimentos: como a necessidade de conhecer e disseminar as dissidências, de buscar lógicas outras que antecipem o fim de determinados mundos - ainda que no espaço ficcional -, que coloquem em tensão o papel da mediação, que apostem nas mesclas de gêneros, que provoquem; tais gestos evidenciam as construções de caminhos possíveis para a literatura, em sua ambiguidade de libertação e censura, estranha instituição.

Ao especular novos modelos de crítica/ produção literária, parece-nos muito importante pensar de modo específico o que tal crítica tem por objetivo analisar, sob o risco de escolhas estratégicas ou de economias textuais que partam de um antigo ponto $\mathrm{A}$, percorram um longo caminho, e retornem ao mesmo ponto A. Afinal, com uma estratégia pouco definida e sem saber de fato com o quê e como se pretende romper, a crítica e/ou a produção literária "permanecerá sempre fiel a esta dupla intenção: conservar como instrumento aquilo cujo valor de verdade ele critica" (DERRIDA, 1971, p.238).
Portanto, desestabilizar as noções hierárquicas de poder em torno daquilo que se considera a norma pode vir a nos aproximar de uma crítica literária outra, quem sabe algo nascido, criado e frutificado a partir da teoria crítica feminista interseccional y dos feminismos negros.

\section{Referências}

BORGES, Rosane. Prefácio à edição brasileira: das perspectivas que inauguram novas visadas. In: bell hooks. Olhares negros: raça e representação. São Paulo: Elefante, 2019.

DALCASTAGNÈ, Regina. Um território contestado: literatura brasileira contemporânea e as novas vozes sociais. Iberic@l: Revue d'études ibériques el ibéro- américaines, Paris, FR: Universidade Paris - Sorbonne, no 02 , p. 13-18, 2012.

DALCASTAGNÈ, Regina. A crítica literária em periódicos brasileiros contemporâneos: uma aproximação inicial. Estudos de Literatura Brasileira Contemporânea, Brasília: UBN, n. 54, p. 195-209, 2018.

DERRIDA, Jacques. A estrutura, o signo e o jogo no discurso das ciências humanas. A escritura e a diferença. Trad. Maria Beatriz Marques Nizza da Silva. São Paulo: Perspectiva, 1971.

DERRIDA, Jacques. Essa estranha instituição chamada literatura: Uma entrevista com Jacques Derrida. [s.l.] Editora UFMG, 2014.

DERRIDA, Jacques. A lei do gênero - Jacques Derrida. Revista TEL, v. 10, n. 2, p. 250-281, 2019.

FOUCAULT, Michel. História da Sexualidade: A vontade de saber. São Paulo: Paz e Terra, 2014.

hooks, bell. Olhares negros: raça e representação. São Paulo: Elefante: 2019.

INÁCIO, Emerson. Desmontar a ordem, abrir as parábolas: A lei do género e o género fora da lei. Cadernos de Literatura Comparada, v. 35, p. 357-368, 2016.

LORDE, Audre. Irmã Outsider. Belo Horizonte: Autêntica, 2019. p. 135-139.

NATALI, Marcos P. Além da Literatura. Rev. Literatura e Sociedade, São Paulo: USP, v. 11, no 9, 
p. 30-43, 2006.

NASCIMENTO, Tatiana. 07 notas sobre o apocalipse ou poemas para o fim do mundo. $1{ }^{\mathrm{a}}$ ed. Rio de Janeiro: Garupa e Kza1, 2019a.

NASCIMENTO, Tatiana. Cuírlombismo literário. São Paulo: N-1, 2019b.

PATROCÍNIO, Stela. Reino dos bichos e dos animais é o meu nome. Rio de Janeiro: Azougue Editorial, 2001.

SANTOS, Ariadne. C. o falatório de Stela do Patrocínio e o discurso da crítica literária: variações. 2019. Dissertação (Mestrado em Estudos Comparados de Literaturas de Língua Portuguesa) - Faculdade de Filosofia, Letras e Ciências Humanas, Universidade de São Paulo, São Paulo, 2019.

SANTOS, Claudiana. G. dos. A Bruta Flor do Querer: amor, performance e heteronorma- tividade na representação das personagens lésbicas. 2018. Dissertação (Mestrado em Estudos Comparados de Literaturas de Língua Portuguesa) - Faculdade de Filosofia, Letras e Ciências Humanas, Universidade de São Paulo, São Paulo, 2018.

SPIVAK, Gayatri. Pode o subalterno falar? Trad. Sandra R. Goulart Almeida, Marcos Pereira Feitosa, André Pereira Feitosa. Belo Horizonte: UFMG, 2010.

SOARES, Dionísio 0. A literatura apocalíptica: o gênero como expressão. HORIZONTE - Revista de Estudos de Teologia e Ciências da Religião, v. 7, n. 13, p. 99-113, 2008. Disponível em http://200.229.32.43/index.php/horizonte/ article/view/425. Acesso em: 10 out. 2020.

Recebido em: 15/10/2020

Aprovado em: 12/11/2020 